\title{
A fluidez do bem e do mal: a família tradicional carioca em $A$ vida invisível de Eurídice Gusmão
}

\section{Vanessa Leal Nunes Vieira ${ }^{1}$}

Resumo: Este artigo tem como objetivo analisar o texto literário A Vida Invisível de Eurídice Gusmão, escrito por Martha Batalha em 2016, sob algumas das formações discursivas da classe burguesa que definem o que seriam comportamentos adequados e inadequados para a atuação da mulher na sociedade. Comportamentos desviantes da norma seriam vistos como reprováveis, suspeitos, e ameaçadores à ordem social e podem ser analisados através das personagens Guida, Maria Rita e Filomena em oposição ao personagem de Eurídice, que tenta frequentemente encaixar-se no padrão. O romance oferece o panorama histórico da década de 40 no Rio de Janeiro; período essencial de transição política e trabalhista na história do Brasil. Em sua análise, foram utilizados livros e artigos teóricos de diferentes autores que trabalham as questões abordadas pelo texto literário, para que se entendesse como o ser humano processa a influência dos discursos hegemônicos e de que forma eles se espelham na vida das pessoas que não pertencem à classe dominante, refletindo seus avessos. Como resultado, é possível perceber as linhas tênues entre o adequado e o inadequado nos valores e comportamentos rejeitados, da relação entre o desejo da classe dominante para que se perpetue o modelo econômico vigente e as diversas estratégias utilizadas para a dominação do sexo feminino, que tem sua culminância nas violências física e psicológica. Palavras-chave: Análise do discurso. Literatura brasileira contemporânea. Martha Batalha. A Vida Invisível de Eurídice Gusmão.

\section{Literatura e discurso}

Em A Vida Invisivel de Eurídice Gusmão, a autora Martha Batalha imprime comentários ácidos e uma ironia sagaz, dignas de uma escritora e jornalista do século XXI, enquanto narra a vida na década de 40 , com

1 Bacharel em Letras Inglês-Literaturas pela Universidade do Estado do Rio de Janeiro (UERJ), especializada em Leitura e Produção Textual pela Estácio de Sá e aluna do mestrado pela Universidade Federal Fluminense (UFF) em Literatura Brasileira e Teoria da Literatura. 
foco no desenvolvimento das personagens femininas. Para além de noções limitadoras de bem e mal, que voltam a figurar nos dias de hoje em discursos vazios sobre uma suposta conduta de "pessoa de bem" (conectada a questões de poder econômico), o livro aponta as linhas tênues que formam as nossas relações sociais e nos dá pistas sobre certos comportamentos enraizados. Para explorar essas questões, autores como Michel Foucault, José Luiz Fiorin e Virginia Woolf serão utilizados como referência, para estudo dos discursos de poder e das ideologias que cercam nossa sociedade, junto a pesquisadores, como Magali Engel e Maria A. D'Incao, que exploram o fim do século XIX e o início do século XX em termos de relações interpessoais, da posição da mulher burguesa na sociedade e da ascensão da psicanálise.

No século XIX, a sociedade brasileira assistiu a consolidação do capitalismo, a ênfase maior na vida urbana e a ascensão da burguesia e de seus valores. Reorganiza-se então a vida doméstica, a partir das famílias patriarcais do sistema escravista, para atender a demanda trabalhista e urbana (D'INCAO, 2017). Nas ruas, reformas higienistas aconteciam para que as relações pudessem formar-se de modo "civilizado": cortiços, grupos marginais, relações comerciais questionáveis e boêmia eram combatidas pela imprensa e proibidas por lei (RAGO, 2014). A pobreza deixou de ser tolerada no centro da cidade e campanhas públicas passaram a excluir grupos marginais dos centros urbanos, deixando claros os limites e as distâncias sociais.

Como a classe dominante passa a ser de modo definitivo a classe burguesa, ela traz junto a si uma formação ideológica que passará a vigorar e servir de modelo para vários discursos.

A ideologia [...] é determinada em última instância, pelo nível econômico. [...] O modo de produção determina as ideias e os comportamentos dos homens e não o contrário. [...] A ideologia dominante é a ideologia da classe dominante. No modo de produção capitalista, a ideologia dominante é a ideologia 
burguesa. (FIORIN, 2012, p. 30-31)

A diferenciação dos ambientes público e privado que limitou o convívio e a distância social entre a classe burguesa e o povo, valorizou a intimidade doméstica sob a égide de um discurso religioso que valorizava um lar aconchegante e receptivo ao marido que voltasse do trabalho. Os filhos ficariam seguros durante a primeira infância, sendo cuidados e educados pela mãe - que ficaria em casa -, longe dos perigos e de relacionamentos sociais tidos como "questionáveis" (amas, negras e moleques), que aconteciam na rua (D'INCAO, 2017). Às mulheres brancas, casadas normalmente pelos pais em função da ascensão social ou manutenção do status, é reforçada a ideia de que a felicidade só seria plenamente atingida dentro dos valores familiares, e que o sucesso desses valores depende delas.

Em outras palavras, significavam um capital simbólico importante. Embora a autoridade familiar se mantivesse em mãos masculinas, [...] esposas, tias, filhas (e serviçais) cuidavam da imagem do homem público; esse homem aparentemente autônomo envolto em questões de política e economia. [...] Considerada base moral da sociedade, a mulher de elite, esposa e mãe da família burguesa deveria adotar regras castas no encontro sexual com o marido, vigiar a castidade das filhas, construir uma descendência saudável e cuidar do comportamento da prole. (D’INCAO, 2017, p. 229-230)

O livro de Martha Batalha inicia em uma explicação sobre o casamento dos personagens Eurídice e Antenor, deixando claro que este só se concretizou em função de uma doença que acometeu a tia dele, fazendo com que esta não pudesse mais lavar suas roupas ou "fazer canja”. Aparecem então duas representantes que assimilaram totalmente o discurso da felicidade doméstica: o papel servil da mulher que está por trás do homem, 
fazendo com que a casa funcione.

Logo depois, a narradora (que a todo momento conta a história como se fosse uma conhecida da família) nos oferece um diagnóstico da base emocional sobre a qual se desenvolverá a história dessa nova família construída: o lençol de Eurídice não amanhece com a mancha de sangue após a noite de núpcias e Antenor grita chamando-a de "vagabunda", pensando inclusive em devolvê-la à família de origem. Denuncia-se o discurso que reduz o valor feminino à castidade e à obrigação sexual unicamente para o casamento, dando espaço para que o homem agrida a mulher caso ela não corresponda ao ideal feminino. O termo "vagabunda" relaciona a mulher com a impureza da rua, principalmente quando Antenor questiona a vida de Eurídice anterior ao casamento com a pergunta "Por onde raios você andou?" (BATALHA, 2016, p.10). É interessante notar como o comportamento de Antenor, que se escora na religião e no comportamento do "bem" reflete em uma agressão, transforma-se no que é vil.

Como esclarece Maria Ângela D’Incao (2017), a virgindade feminina era uma exigência fundamental. Independentemente do valor ético ou religioso em si, a virgindade funcionava para manter o status da noiva como objeto de valor econômico e político. É claro que para as mulheres aderirem a esse projeto, o valor da ideologia religiosa (que tende a estar em conjunto com a política) era o que tinha mais peso. $\mathrm{O}$ controle do corpo feminino trata-se, como diz Foucault (2010), do ponto de apoio para as relações de poder: utiliza-se um discurso para a proteção da alma e de que esta só tem valor se o próprio corpo for controlado.

Seguindo-se os dias na residência dos Gusmão Campelo, Eurídice só não é devolvida por dedicar-se a compensar o acontecido na lua-demel. Cozinhou o melhor que podia, lavou, passou e arrumou a cabeça de Antenor para que ele percebesse que "além de saber desaparecer com os pedaços de cebola na comida, lavar e passar muito bem, ela falava pouco e tinha um traseiro bonito." (BATALHA, 2017, p.11) Tiveram dois filhos: 
uma menina e um menino. E tomando para si a responsabilidade de não mais aumentar a família, Eurídice engordou tudo o que podia esperando um desinteresse sexual do marido.

Ironicamente, Antenor não é um homem de grandes posses e se insere muito mais na condição de trabalhador assalariado do que na de burguês. Acontece que as formações ideológicas que dão base ao discurso hegemônico, enquanto fala e construção da classe dominante, desenvolvemse no tempo por meio da reprodução coletiva. Segundo Fiorin (2012), o ser humano vê o mundo de acordo com as formações discursivas que assimila durante o processo de aprendizagem linguística e reproduz esses discursos em sua fala e ações: "Assim como uma formação ideológica impõe o que pensar, uma formação discursiva determina o que dizer" (FIORIN, 2012, p.32). Antenor, portanto, é um homem que entrou na consciência social e tomou o discurso da submissão econômica e sexual da mulher para si, somando à sua própria interpretação de mundo, reproduzindo-o.

É interessante observar que os anos 40 foram conturbados no âmbito social e econômico. No macro, o mundo atravessava o caminho que levaria ao fim da segunda grande guerra; no micro, o Brasil passa pelo Estado Novo autoritário de Getúlio Vargas, ao mesmo tempo em que este tinha autorizado o voto feminino facultativo em 1934 e que cria a CLT (Consolidação das Leis do Trabalho) em 1943. Também é notável o desenvolvimento do movimento feminista e a inserção da mulher nos espaços de trabalho, principalmente em função das grandes guerras. No início da década de 40 não se tinha publicada ainda a clareza de Simone de Beauvoir; mas Virginia Woolf já havia denunciado ao mundo, em 1931, a importância de as mulheres "assassinarem o anjo do lar" (WOOLF, 2012, p.11). Sendo o anjo, a mulher doméstica e dócil contida em cada fêmea.

Sabe-se que, apesar dos avanços trazidos pelo início do século XX, o discurso patriarcal é presente na sociedade desde muito antes do século XIX. A desigualdade entre homens e mulheres foi assumida como um 
reflexo da natureza ou desejável aos olhos de Deus, se formos identificar um argumento religioso, e sempre como necessária para a perpetuação da espécie. Qualquer coisa que ouse fugir deste discurso é vista como uma ameaça a ser corrigida.

Inclusive, durante séculos, foi negado às mulheres o simples direito de ler e estudar. A educação e formação social erudita eram exclusivas aos homens. E como objeto comum de estudo em toda a formação masculina, está o "poder maior": a linguagem. Como coloca Roland Barthes (2017, p.12-13), é nela [linguagem] que se inscrevem os discursos de opressão. É dela que se utilizam para influenciar, julgar, aprisionar, mas também para libertar se quiserem. Também Foucault aponta essa relação entre conhecimento e opressão quando alega que "Não há relação de poder sem constituição correlata de um campo de saber, nem saber que não suponha e não constitua ao mesmo tempo, relações de poder". (FOUCAULT, 2010, p. 30).

A privação educacional fez com que o poder da linguagem, a consciência de como usar o código linguístico em um discurso para influenciar e moldar a sociedade, ficasse concentrado em mãos masculinas, principalmente nobres e religiosas sob o pretexto de que era para o bem comum. Ainda segundo Foucault (2010), o poder hegemônico não se constitui apenas de uma característica repressora, mas também produtora. Faz uso do discurso para estabelecer o modo correto de agir tanto quanto repreende determinadas práticas. Por exemplo, no âmbito corporal, existem técnicas de controle dos corpos que servem a uma ideologia política - estatal e religiosa - que busca fazê-los produtivos e dóceis. $\mathrm{Na}$ questão feminina, privando a mulher do controle de seus corpos, reprimese a condição fundamental de sua integridade física e psicológica, fazendo com que a maternidade seja atrelada à condição de trabalho forçado (FEDERICI, 2017 p. 182). Controlando o corpo, controla-se a mente.

Assim, as formações discursivas engendradas na sociedade de que as 
mulheres seriam emocionalmente instáveis e intelectualmente inferiores, foram incansavelmente reproduzidas por toda sociedade histórica com algum projeto de poder. Elas precisariam continuar virgens até o casamento e, por serem fisicamente frágeis, não deveriam trabalhar fora de casa, onde estariam protegidas e poderiam exercer as funções primordiais de esposas e mães. $\mathrm{O}$ discurso burguês e a separação das esferas pública e privada oficializa a inferioridade feminina e criam vulnerabilidades sociais:

Em nome da preservação da esfera privada, os direitos dos indivíduos na família foram menos protegidos do que em outros espaços, ainda que neles as garantias também fossem incompletas e diferenciadas de acordo com as posições sociais. A garantia de privacidade para o domínio familiar e doméstico foi vista como uma das ferramentas para a manutenção da dominação masculina. (BIROLI, 2014, p.32)

São notáveis as tentativas recentes de disseminar a ideia de uma falsa dependência mútua entre marido e esposa e de que a valorização da mulher também deve se estender a outras esferas da vida depois de que ela se torna mãe. Porém, na prática, o trabalho não-remunerado exercido no âmbito doméstico pelo sexo feminino, limita sua possibilidade de atuação em trabalhos assalariados para que haja apenas uma dedicação ampliada ao marido, à casa e aos filhos; sendo essa ideologia trabalhista baseada na atribuição de papéis fixos e distintos, resultante de uma consideração de talentos diversos para cada sexo (BIROLI, 2014, p.50).

Propagou-se a expectativa de que a mulher fosse capaz de renunciar a si mesma e aos seus interesses para que fosse valorizada a partir da capacidade de cuidar do outro. Uma vez considerada aluna brilhante, dedicada e interessada, Eurídice aplica essa personalidade esforçada também na vida doméstica; de modo a tornar-se um modelo exemplar do discurso patriarcal internalizado. Mesmo sabendo que a domesticidade não é valorizada: "Ninguém vale muito quando diz ao moço do censo que 
no campo de profissão ele deve escrever as palavras 'do Lar"' (BATALHA, 2016, p. 11), ela se esmera em todo trabalho que se propõe a realizar. E quanto mais se esmera, mais se anula.

Eurídice, vejam vocês, era uma mulher brilhante. Se lhe dessem cálculos elaborados ela projetaria pontes. Se lhe dessem um laboratório ela inventaria vacinas. Se lhe dessem páginas brancas ela escreveria clássicos. Mas o que lhe deram foram cuecas sujas, que Eurídice lavou muito rápido e muito bem, sentando-se em seguida no sofá, olhando as unhas e pensando no que deveria pensar. (BATALHA, 2016, p.12)

Ela representa perfeitamente o papel da mulher sem voz e sem vontade própria. Eurídice é o que achou que queriam que fosse. E é realmente quando decide não pensar, que Eurídice passa a agir. Aproveitando o tempo em que se via fadada a passar em casa e que uma de suas obrigações era justamente a de cozinhar, Eurídice resolve dedicar-se inteiramente à culinária. Porém, não se dedica a uma culinária rotineira, mas sim criativa, que exigia que fosse à rua para comprar ingredientes diferentes dos que tinham em casa. Escolhia a dedo uma receita do "Livro de Tia Palmira", colocava o "vestido de sair" e ia passear. Só nessa sequência de atos, Eurídice se remete às tradições femininas passadas adiante (ao consultar o livro de receitas) e inventa uma nova mulher em si mesma, mais criativa e desejante. A sua vida doméstica, invisível, contrapõe-se à identidade que inventa para si ao colocar o "vestido de sair". E temos aqui a primeira tentativa de apropriação (ao invés da internalização) do discurso patriarcal hegemônico, como traço de uma narrativa contemporânea: Eurídice tenta se apropriar da diferença entre a vida pública e privada, usando-a a seu favor.

Depois de um tempo pegando inspiração no livro de receitas, Eurídice naturalmente passa a desenvolver suas próprias ideias, resolvendo 
colocá-las no papel e escrever um livro. O ato de escrever para uma mulher, mesmo sendo apenas um livro de receitas, retomam um certo "memorialismo literário" que

reelaboram-se, através de um eu poético, imagenslembranças que consistem na revivência afetiva de acontecimentos evocados por sensações que retornam renovadas; compondo-se a ficcionalidade do texto, pois, da recriação literária do passado emerge o verossímil, como uma experiência recordada. (SOARES, 2007, p.26)

O trabalho a dignifica e ela se permite exercer sua criatividade para sair da domesticidade. Eurídice toma consciência de si enquanto foge do arroz e feijão da própria vida e mais à frente no texto, descobrimos que Eurídice recupera sua vontade de escrever e desafia tudo o que havia internalizado até aqui: entra na faculdade de história e decide escrever um livro "sobre a história da invisibilidade" (BATALHA, 2016, p.164). Entretanto, é importante pontuar aqui que Antenor não percebeu nada de diferente na comida, ou em sua esposa, durante todo o tempo. Para ele, era apenas Eurídice cozinhando, fazendo nada mais do que sua obrigação. E quando ela apresenta ao marido o resultado de toda a sua ciência na cozinha, Antenor cai na gargalhada: "Deixe de besteiras, mulher. Quem compraria um livro feito por uma dona de casa?" (BATALHA, 2016, p.32). $\mathrm{O}$ trabalho feminino é desprovido de valor frente ao trabalho masculino, sendo digno apenas de chacota.

A situação feminina não se trata apenas das inúmeras tentativas de inserção no mundo do trabalho e das tomadas de consciência sobre a própria dignidade. A posição social das mulheres, mais do que diferente, é marcada pela subalternidade. Eurídice é um exemplo de todas as que não tem acesso nem às posições de poder, nem ao controle dos bens materiais; sofrendo privações em sua própria casa, onde supostamente seria a "rainha 
do lar". Por essa razão, estão mais sujeitas à violência e à humilhação (MIGUEL, 2014, p. 102). Eurídice volta para a cozinha de cabeça baixa, pega o livro e o joga no lixo. Joga a si mesma no lixo. O projeto pessoal no qual ela tinha colocado tanto tempo e dedicação, é considerado, por Antenor, tão importante quanto os restos de comida. E é através dos olhos dele, impregnados pelo discurso social, que ela se enxerga momentaneamente.

Como dito antes, Eurídice aprende sobre si enquanto escreve o livro, toma consciência sobre suas capacidades e sua individualidade. Mesmo sofrendo pressão de Antenor, Eurídice levanta-se de madrugada, às três da manhã, e vai até o lixo resgatar o caderno de receitas. Resgatar a si mesma. Limpa a capa, enxuga as páginas o quanto consegue e o guarda ao lado dos exemplares da enciclopédia, na estante da sala. Nos dias que seguem, Eurídice não consegue se conformar mais com a rotina. $\mathrm{O}$ discernimento ganho com o próprio trabalho não pode mais ser perdido, o que deixa a personagem absorta em pensamentos, tentando achar um novo projeto ao qual dedicar-se.

Como traço da escrita contemporânea, a narrativa de Martha Batalha descreve o íntimo psicológico das personagens femininas. Com Eurídice, que no texto simboliza todas as mulheres de sua época, ressalta-se a todo o tempo a importância da ocupação física para evitar a depressão e sua inconformidade frente à rotina familiar: "Nessas horas perdidas ela podia sentir a solidão se transformar em angústia, a angústia se transformar em loucura e a loucura sussurrar-lhe calma e firme: um dia eu te pego..." (BATALHA, 2016, p.39) E tendo em si a carga de todas as mulheres, ela se encanta novamente por outra atividade marcada pela carga histórica feminina: corte e costura. Ao atender o desejo de adquirir uma máquina Singer, Eurídice começa o processo de se remendar. Ela atende à sua dignidade e faz-se inteira novamente.

Quando cozinhava, ela expressava sua criatividade e seu símbolo era "o vestido de sair"; sua aparência passa a ter importância e o ato de 
"vagar" pelas ruas deixa de ter a carga negativa que Antenor impôs quando a chama de "vagabunda". Quando escreveu suas receitas, o símbolo era o "caderno preto"; sua voz passou a importar através da escrita. Quando começa a costurar, o símbolo é a "máquina Singer"; seu esforço importa. E importa tanto, que Eurídice vê a chance de ganhar dinheiro com ele. Vê-se a segunda tentativa de apropriação da vida pública: é através do ambiente doméstico que Eurídice vai começar a produzir vestidos, terninhos e saias para vender às outras mulheres do bairro. Estas, por sua vez, só incentivam a vizinha e compram de seu trabalho por acreditar no rumor espalhado de que ela precisa trabalhar, em razão de Antenor estar passando por um momento difícil no emprego.

O trabalho feminino não é visto como vontade ou interesse próprios, mas sim como último caso de necessidade monetária da família. A domesticidade da mulher branca e burguesa tem relação direta com a socialização coletiva de meninas e meninos, com a construção diferenciada de possibilidades e horizontes desde a infância. A socialização em função dos discursos sobre as expectativas sociais para cada sexo, sempre foi a base do acesso diferenciado a recursos e à disponibilização do espaço para dedicação à projetos e ao tempo livre; e que faz com que homens e mulheres tenham uma interpretação diferente - e preconceituosa - em relação ao exercício da autonomia laboral (BIROLI, 2014. P. 113). Estando essa interpretação social acerca do trabalho, infelizmente, bem retratada na esfera literária em questão, Antenor descobre o projeto de costura e, irritadíssimo, humilha Eurídice com gritos de forma que toda a vizinhança escute. Sua mulher trabalhando ofende sua masculinidade, definida exatamente pela possibilidade específica de colocar dinheiro e comida em casa. "Iam achar que ele era homem de menos, porque a mulher trabalhava demais" (BATALHA, 2016, p.52).

Eurídice inicialmente omite o trabalho por ter total consciência de que nunca teria sido apoiada pelo marido; e este, que não presta atenção 
na esposa, só descobre meses depois - o que vem como um agravante. A ofensa também tem a ver com o fato de ele entender que Eurídice pode ser uma mulher independente; e que como autônoma, pode escolher abandonar o projeto doméstico histórico, em que a fêmea é o capital simbólico do homem e que cuida para que ele obtenha sucesso profissional através de uma boa imagem pública. Com poder de escolha, ela se torna uma ameaça. A mulher branca da década de 40 no Brasil ainda é o "anjo do lar”. E algo está errado se esta criatura frágil resolve trabalhar por dinheiro. Ele trabalha. Ela aproveita a domesticidade e cuida da casa, de graça.

- Mas Antenor, eu também gosto de trabalhar.

- O seu trabalho é cuidar da casa e das crianças.

[...] Eu preciso de uma mulher dedicada ao lar. É sua responsabilidade me dar paz de espírito pra eu sair e trazer o salário pra casa. (BATALHA, 2016, p. 53)

E depois desta briga, Eurídice abaixa a cabeça e se cala. Ela se submete definitivamente ao marido, sentindo-se desmotivada até no cuidado com os filhos. Enquanto trabalhava com a costura, Eurídice fomentava a curiosidade de Cecília e Afonso, fazia o dever de casa com os dois, era uma mulher agitada e seus olhos brilhavam de empolgação. Bastava olhar para um tecido e sua criatividade começava a aguçar. Se ouvindo e sendo inteira para si mesma, Eurídice conseguia se dividir entre os filhos. Muito em função do olhar contemporâneo de Martha Batalha, não é o casamento e a maternidade que traz satisfação a Eurídice; era a dignidade da vida pública, do trabalho remunerado, que fazia com que ela pudesse dar significado, um propósito, para a vida doméstica. Porém, a imposição da voz masculina com palavras cada vez mais torpes utilizadas por Antenor, fez com que Eurídice se negasse novamente ao lugar da mulher dentro da casa. Calada e submissa. Nas palavras de Woolf:

O opressivo e sufocante era o que podemos chamar 
de educação negativa, que decreta não o que se pode fazer, e sim o que não se pode fazer. Provavelmente apenas as mulheres submetidas a ela podem entender o peso do desestímulo ao ouvirmos constantemente que, como mulheres, nunca se espera muita coisa de nós. (WOOLF, 2018, p. 54)

Eurídice havia sentido o gosto da independência antes de ser submetida à "educação negativa" que vinha do marido e de ser desestimulada a perseguir uma independência financeira e trabalhar com o que gostava. Como acontece no episódio do livro de receitas, não há valorização da criatividade e do trabalho feminino se ele não serve aos ideais da família burguesa. E se não tem serventia ao discurso dominante da família branca tradicional, o comportamento deve ser rejeitado como desviante ou loucura.

\section{Loucura e fuga}

Falaremos agora de como na obra de Martha Batalha, conta-se também a história da infância de Eurídice e de Antenor. O leitor passa a conhecer Guida, a irmã de Eurídice que foge de casa, e a mãe de Antenor, Maria Rita, que comete suicídio quando este era apenas um menino:

Antenor cresceu numa casa de poucas refeições e de muita sujeira. A única coisa estruturada naquela família eram os dísticos e tercetos recitados pela mãe. [...] Feliciano chegava da repartição e se surpreendia com as façanhas da mulher [...] A cozinha estava sob o comando de baratas, passeando sobre as crostas de comida nas louças. $\mathrm{Na}$ única poltrona que não servia de cabide, estaria Maria Rita ainda de camisolão, de frente para o caderninho de versos. (BATALHA, 2016, p.77) 
Maria Rita, a mãe das "seis crianças que produziu antes de completar vinte e cinco anos" (sendo uma delas, Antenor), era poeta. Ou melhor, gostaria de ter tido a oportunidade de ser poeta, mas casou-se com Feliciano e teve 6 filhos. $\mathrm{O}$ marido, funcionário público, apesar de dizer apoiar sua arte, saía para o trabalho e quando retornava esperava encontrar comida pronta, casa limpa e filhos limpos; afazeres pelos quais ele não se sentia responsável. “Todos sabiam que Maria Rita não era talhada para aquela vida” (BATALHA, 2016, p.78). Como pontua Magali Engel (2017, p.333), a sociedade entende que o sexo feminino está naturalmente predestinado ao exercício do papel doméstico. A incapacidade ou recusa em cumpri-lo é visto como resultante da natureza vacilante da mulher e sendo, ao mesmo tempo, qualificada como antinatural.

Foi com base na diferença entre os sexos, e servindo para endossar o discurso capitalista da divisão das esferas de trabalho, que nasceram fortes teorias científicas na medicina e na psiquiatria (com traços de crenças populares) entre o final do século XIX e o início do século XX. A loucura feminina foi fartamente estudada por psiquiatras e psicanalistas desde o século XIX, sendo qualquer distúrbio mental associado inicialmente ao órgão genital feminino. Para somar à dominação econômica, religiosa e política, teve início um outro discurso acerca das mulheres: o de adequação sexual. Partia-se do princípio de que o instinto materno feminino suprimia o instinto sexual e aquela que sentisse qualquer desejo voluptuoso, que ultrapassasse os limites sociais estabelecidos para uma mulher, seria considerada anormal, perigosa. (ENGEL, 2017, p.339). Muitas mulheres que não se encaixaram, ou que paravam de se encaixar, no padrão social e sexual exigido (mãe e esposas perfeitas) ou fugiram, como Guida, ou foram internadas como doentes mentais. Maria Rita opta pelo suicídio. Sendo assim, podemos entender que

Um poder dominante pode legitimar-se promovendo crenças e valores compatíveis com ele; naturalizando 
e universalizando tais crenças de modo a torná-las óbvias e aparentemente inevitáveis; denegrindo ideias que possam desafiá-lo; excluindo formas rivais de pensamento; mediante talvez alguma lógica não declarada, mas sistemática; e obscurecendo a realidade social de modo a favorecê-lo. (EAGLETON, 1997, p.198)

Atribuiu-se então à mulher o caráter emocional; ela estaria mais ligada à natureza, à sensibilidade nutritiva e aos sentimentos aflorados. No homem, identificou-se um caráter cultural, mais ligado à razão lúcida e à capacidade de decisão. Por ser entendida como mais sensível e emocionalmente irracional - além de frágil, bonita, submissa e doce -, também foram atribuídas qualidades negativas às mulheres, como a perfídia, a sedução e a amoralidade sexual (traços de Eva) - fazendo com que a visão científica e disseminada sobre o sexo feminino fosse profundamente ambígua e considerada incompatível com vida pública.

Guida é a representação desse lado mais ousado e sedutor e a infância de Eurídice foi marcada pela presença da irmã. Era alguns anos mais velha que Eurídice, o suficiente para que tudo o que ela fizesse fosse curioso, de encher os olhos. Guida passava batom vermelho, Eurídice também queria. Guida lia romances e o "Jornal das Moças" e Eurídice achava que tudo o que a irmã falava tinha um quê de ciência e mistério. Guida saía com as amigas "por aî" e Eurídice achava que o tal "por aî" continham experiências exóticas e incríveis. Eurídice ficou menstruada e foi Guida quem a explicou as causas e as razões. Os pais das duas eram rígidos e tinham projetos para as filhas. Seu Manuel trabalhou o suficiente para que Guida e Eurídice pudessem fazer aulas extras depois da escola como francês e música, para que um dia fossem consideradas interessantes por um rapaz e formassem a própria família. Nada além disso. Não foram ensinadas a desejar.

Guida, um dia, aparece com Marcos em casa. Marcos foi interrogado por Seu Manuel: morava em Botafogo e era estudante de medicina. Dados 
que futuramente descobriria serem mentira. Porém, com base naquelas afirmações, Guida e Marcos namoraram no sofá da sala por um tempo. Depois, Guida começou a ficar cada vez mais distante da família, até mesmo de Eurídice, e fugiu. Levou as roupas e os livros e nunca mais apareceu em casa; deixando Eurídice sem nenhuma resposta, mas com um peso enorme. A vida adulta de Eurídice foi marcada pela ausência da irmã.

A psiquiatria e a medicina legitimaram o poder patriarcal burguês por um bom tempo. Consolidaram na mente leiga da sociedade que o gênero feminino tinha predisposição à loucura; à imoralidade sexual se não controladas; e que eram incapazes de exercer a cidadania ou os estudos de modo a desenvolvê-los profissionalmente (ENGEL, 2017, p.333). Guida e Maria Rita, a mãe de Antenor, são apenas dois exemplos literários que mostram o quão inquietante e sufocante essa limitação social realmente foi para a mulher e duas das muitas alternativas reais de fuga.

Maria Rita encontrava retiro em seus poemas; vendo-se impossibilitada de desenvolver uma carreira profissional, deixou-se fugir da realidade entrando em depressão para depois concretizar sua fuga mental com o suicídio. Já Guida começa sua fuga física ainda em casa, isolando-se da família (e das exigências familiares) gradativamente até desaparecer de modo definitivo. Para Eurídice, frente ao sumiço da irmã, sobra a exigência de compensar a filha, esposa e mãe que Guida não foi. Eurídice, que sempre foi boa em tudo que se dispunha a fazer, internaliza o discurso dominante em função da fragilidade de perder a irmã mais velha e de querer se equiparar à mulher exemplar que os pais gostariam que as duas fossem. Eurídice foge de si mesma para se tornar a imagem perfeita de Eurídice e Guida juntas.

Quando Guida torna-se mãe e é abandonada por Marcos, a única que a acolhe é Filomena, mulher "que tinha sido a prostituta mais requisitada do Estácio" (BATALHA, 2016, p.109) e se viu obrigada a parar por contrair sífilis. Filomena decide tomar conta de crianças para que as 
mães mais pobres - "prostitutas, operárias e funcionárias do comércio" pudessem trabalhar e logo torna-se "a babá mais requisitada do Estácio" (BATALHA, 2016, p.110). O arco de Filomena e Guida é um espelho para o arco de Eurídice e Antenor, em que todos os valores patriarcais das "famílias de bem" viram do lado avesso - mas também se encontram refletidos. Filomena, essa mulher "vagabunda" como Eurídice jamais foi, "de sorriso desfalcado e hálito podre" era a mulher que "sorria muito e gargalhava ainda mais", sempre de bom humor. Uma mulher que "não podia com mãe desamparada" e que se torna "cara-metade para Guida" (BATALHA, 2016, p.111). E apesar das duas criarem Chico, como duas mães mesmo e darem todo o carinho a ele, o menino

cresceu um pouco e viu que a coisa não era bem assim. Famílias como a dele não existiam. Tinha que ter um pai, como aquele que aparecia nas cartilhas da escola, de terno escuro e cabelo lustroso. [...] Apesar dos pirulitos e carinhos e mingaus, Chico foi crescendo meio revoltado por ter uma vida que era boa mas não era a certa. Por ter duas mães tão doces quanto renegadas. Por que aquela mulher tinha trocado de calçada e soltado um cuspe junto com um marafona ao ver Filomena na rua? Por que naquele dia na feira chamaram sua mamãe Guida de mulher da vida, e por que sua mamãe ficou muito brava quando ele perguntou qual era o problema em ser uma mulher da vida, já que todas as mulheres eram da vida, e não da morte? Por que Filomena só podia chegar na igreja depois que a missa começava e sair pouco antes de terminar? Tudo errado, ele pensava, e quanto mais sabia sobre o mundo, mais raiva ele sentia. Preconceito, pobreza, a falta de um pai, a vida dura das mães, todas essas coisas formavam as duas pontas de um mesmo barbante [...]. (BATALHA, 2017, p.117)

É interessante analisar essa passagem pelos olhos de Chico 
e identificar as duas pontas do barbante. Em uma das pontas está a independência de Guida e Filomena, que trabalham e correm atrás da sobrevivência: Guida que foi abandonada pelo homem que a enganou com promessas de amor; Filomena que foi usada por homens na Zona, muitos casados. Ambas renegadas socialmente sob os critérios da religião e da moral hegemônica. Moral esta que rege a outra ponta do barbante, a ponta de Eurídice, a mulher branca e recatada, de família.

Faz-se possível a percepção de que as sanções sociais se originam a partir de uma política repressora do corpo e da divisão dos papéis sociais, não só pela pesquisa sobre a história, mas muito pelo presente. Atualmente, no Brasil, valida-se no cargo público de Ministro dos Direitos Humanos uma pastora evangélica que especifica publicamente que "meninas vestem rosa e meninos vestem azul". Sim, é uma mulher em um alto cargo político. Porém, ao dar voz ao discurso da divisão social de tarefas - que é o que está por trás da determinação de cores - baseada na afirmação ultrapassada, e falsa, de que homens e mulheres têm aptidões físicas e emocionais diferentes, ela se torna um figurão do discurso hegemônico em si; funciona como uma mensagem de que o estado tem plena ciência das pautas que confrontam o discurso no qual toda a sociedade capitalista se baseou desde o século XIX. E que a ideia é exatamente para que os opositores se calem.

Colocando uma mulher, pastora, que ao fazer uso do poder da linguagem pública para reproduzir o discurso histórico burguês patriarcal enquanto traz de volta - por referência natural e simbólica à sua imagem na igreja - a base religiosa da ideologia de controle corporal, espera-se que outras mulheres, principalmente as atuais feministas, repensem sua má atitude e a tenham como exemplo. Esta atitude governamental é, no mínimo, irresponsável frente aos dados do Anuário Brasileiro de Segurança Pública, que apontam 1.133 feminicídios apenas em 2017 e 221.238 casos de lesão corporal dolosa enquadrados na lei Maria da Penha.

Essa política repressora do corpo da qual se utiliza a religião e o 
governo, resgata as dificuldades pelas quais passam Maria Rita, Guida e Filomena: Uma poeta jovem que não queria ser mãe, uma mãe solo e uma mulher que trabalhou na prostituição e é mal vista pela sociedade burguesa, de forma que precisa até mesmo chegar na igreja com a missa já iniciada e sair antes que acabe, tudo para não ser vista. Mulheres dissidentes da moral hegemônica e indesejadas por aqueles que a impõem.

Fazendo uma análise geral da trajetória de Eurídice Gusmão (assim como de Guida, Filomena e Maria Rita), é possível afirmar que não existe uma natureza específica do ser feminino, apesar de terem tentado impor ou desvendar suas características: santas, prostitutas, pérfidas, sedutoras, suspeitas, loucas. O que se observa é a imposição do discurso econômico, político e religioso de controle sobre a feminilidade e da distribuição de papéis sociais que resulta constantemente em expectativas falhas, violência física e psicológica, reprovação social e repressão sobre o corpo e a sexualidade da mulher.

Pode-se concluir que a razão desse discurso se dá por ele atender às demandas econômicas da classe dominante desde a formação burguesa no Brasil. A Vida Invisível de Eurídice Gusmão, retrata essa estrutura através do memorialismo literário e nos esclarece o quanto de Eurídice pode estar refletido em Guida e vice-versa. Assim como os homens internalizaram o discurso de opressão às mulheres, já que este lhe servia bem; igualmente as mulheres o fizeram, pela falta de educação formal, por receberem o verniz das recompensas sociais - a aceitação da vitória de uma Maria sobre a Eva - e por testemunhar as consequências sofridas por aquelas que fugiam à norma. É a partir da recriação literária do passado que emerge o verossímil, como uma experiência social comum que pode ser recordada.

É importante ressaltar que este trabalho não incluiu a história da 
mulher negra por motivos específicos de extensão. Muitos dos pontos sensíveis na história da mulher branca e de classe média não foram os mesmos para a mulher negra e, estes segundos, merecem uma análise mais profunda. A elas, outras formas de violência foram impostas e outras exigências e análises acerca de comportamentos adequados e inadequados foram feitas; muito em função do histórico brasileiro de escravidão. Este artigo deixa esse tópico em aberto para a continuidade da investigação plural sobre a mulher no Brasil.

\section{Referências}

BARTHES, Roland. Aula. Tradução de Leyla Perrone-Moisés. São Paulo: Cultrix, 2008.

BATALHA, Martha. A Vida Invisível de Eurídice Gusmão. São Paulo, Companhia das Letras, 2016.

BIROLI, Flávia; MIGUEL, Luis F. Feminismo e Política. São Paulo, Boitempo, 2014.

CORTÊZ, Natacha. Os Nomes do Feminicídio. Marie Claire, Rio de Janeiro, Nov. p.76, 2018.

D'INCAO, Maria A. Mulher e Família Burguesa. In: PRIORE, Mary del. (org.) História das Mulheres No Brasil. São Paulo, Contexto, p. 223-240, 2017.

EAGLETON, Terry. Ideologia: Uma Introdução. Tradução de Luis Carlos Borges e Silvana Vieira. São Paulo, Boitempo, 1997.

ENGEL, Magali. Psiquiatria e Feminilidade. In: PRIORE, Mary del. (org.) História das Mulheres No Brasil. São Paulo, Contexto, p. 322-361. 2017.

FBSP - Fórum Brasileiro de Segurança Pública. 12 Anuário Brasileiro 
de Segurança Pública: Sobre o Feminicídio. 2018. Disponível em: https:// dossies.agenciapatriciagalvao.org.br/dados-e-fontes/pesquisa/12oanuario-brasileiro-de-seguranca-publica-fbsp-2017/

FEDERICI, Silvia. Calibã e a Bruxa. Tradução Coletivo Sycorax. São Paulo, 2017, Editora Elefante.

FIORIN, José L. Linguagem e Ideologia. São Paulo, 2012, Ed. Ática.

FOUCAULT, Michel. Vigiar e Punir: Nascimento da Prisão. Tradução de Raquel Ramalhete. Petrópolis, Editora Vozes, 2010.

FRANZ, M.-L von. O Processo de Individuação. In: JUNG, Carl G. et al. $O$ Homem e Seus Símbolos. Tradução de Maria Lúcia Pinho. Rio de Janeiro, Editora Nova Fronteira, 2008.

RAGO, Margareth. Do Cabaré ao Lar: A utopia da cidade disciplinar e a resistência anarquista. São Paulo, Editora Paz e Terra, 2014.

SOARES, Angélica. Adélia Prado: Questões Ideológicas de Gênero no Memorialismo de Bagagem. In: SILVA, Antonio de Pádua Dias da. (org.) Gênero em Questão: Ensaios de Literatura e Outros Discursos. Campina Grande, EDUEP, 2007.

WOOLF, Virginia. Profissões para Mulheres e Outros Artigos Feministas. Tradução de Denise Bottmann. Porto Alegre, L\&PM, 2018.

The fluidity of good and evil: the traditional carioca family in The invisible life of Eurídice Gusmão

Abstract: This article aims to analyze the literary text The Invisible Life of Eurídice Gusmão, written by Martha Batalha in 2016, under some of the discursive formations of the bourgeois class that define which behaviours would be appropriate or inadequate for the performance of women in society. Behaviors that deviate from the norm would be seen as reprehensible, suspicious, and threatening to the social order and can be analyzed through the characters Guida, Maria Rita and Filomena as 
opposed to the character of Euridice, who often tries to fit in the pattern. The novel offers a historical overview of the 1940s in Rio de Janeiro; an essential period of political and labor transition in Brazilian history. In its analysis, books and theoretical articles from different authors who work on the issues addressed by the literary text were used, in order to understand how the human being processes the influence of hegemonic discourses and how they are reflected in the lives of people who do not belong to the ruling class, reflecting its opposites. As a result, it is possible to see the fine lines between what's suitable or inappropriate in the values and behaviors rejected from the relationship between the desire of the ruling class to perpetuate the current economic model, and the various strategies used for female domination, which culminates in physical and psychological violence.

Keywords: Discourse analysis. Contemporary Brazilian literature. Martha Batalha. The Invisible Life of Eurídice Gusmão.

\section{Recebido em: 08/08/2021}

Aceito em: 16/09/2021 